\title{
Effect of 16-Week Blood Flow Restriction Exercise on Functional Fitness in Sarcopenic Women: A Randomized Controlled Trial
}

\author{
Efecto del Ejercicio de Restricción del Flujo Sanguíneo de 16 Semanas sobre \\ la Aptitud Funcional en Mujeres Sarcopénicas: Un Ensayo Controlado Aleatorio
}

\begin{abstract}
Rubens Vinícius Letieri1 ${ }^{1,2}$; Guilherme Eustáquio Furtado²; Paulo Marcelo Nogueira Barros ${ }^{3}$; Mayrhon José Abrantes de Farias $^{1}$; Bruno Fernandes Antunez ${ }^{1}$; Beatriz Branquinho Gomes ${ }^{3}$ \& Ana Maria Miranda Botelho Teixeira ${ }^{2}$
\end{abstract}

LETIERI, R. V.; FURTADO, G. E.; BARROS, P. M. N.; FARIAS, A. M. J.; ANTUNEZ, F. B.; GOMES, B. B. \& TEIXEIRA, A. M. M. B. Effect of 16-week blood flow restriction exercise on functional fitness in sarcopenic women: a randomized controlled trial. Int. J. Morphol., 37(1):59-64, 2019.

SUMMARY: We investigated the effect of the intervention using the BFR method on functional capacity after 16 weeks in elderly women. In a controlled clinical trial, 23 women were randomly allocated into two groups, low-intensity exercise with blood flow restriction $(\mathrm{LI}+\mathrm{BFR}, \mathrm{N}=11$, Age: $69.40 \pm 5.73$ ) and control group (CG, N = 12, Age: $69.00 \pm 6.39)$. The LI + BFR group had a volume of 75 repetitions at 20-30\% of 1RM and 3-4 sets per exercise (30,15, 15 and repetitions with 30" rest between sets). The CG did not undergo any type of exercise. Functional capacity, anthropometry and sarcopenia were verified through a battery of tests before and after 16 weeks. The LI + BFR group had significant improvement in performance in Handgrip strength, Chair Stand, Arm curl, 2.44 Up-and-Go and 6 min walk, Sit-andreach and Back Scratch $(\mathrm{p}<0.05)$ after the intervention. The elderly women were still classified as sarcopenic, despite the improvement in the Muscle Mass Index $(\mathrm{p}<0.01)$. CG did not present significant changes. The BFR method can be an effective in the intervention process using physical exercise as an auxiliary strategy in the control of sarcopenia, providing a physical profile during the aging process.

KEY WORDS: Occlusion training; Elderly; Handgrip strength.

\section{INTRODUCTION}

In recent years, we have seen a growing increase in the number of older people around the world. According to the World Health Organization, the proportion of older people will increase between 2015 and 2050 from 900 million to 2 billion elderly people aged 60 , i.e. a relative increase rate from 12 to $22 \%$ (World Health Organization, 2018). The aging process is progressive, with intrinsic and deleterious characteristics that affect all individuals throughout life (Esain et al., 2017). Related falls and injuries are important implications of aging. At least once a year, about one third of people over 65 years of age fall (Giordano et al., 2016).

Sarcopenia, which is the age-related loss of muscle mass, increases the risk of falls, reduces mobility, functional capacity and is associated with several diseases (Cruz-Jentoft et al., 2010). With advancing age, both skeletal muscle mass and strength tend to decrease, contributing directly to physical dependence (Tieland et al., 2017). This process occurs in both men and women in the aging phase, but the rates of decrease are not the same between age and sex. A previous study reported a reduction in strength in women around the age of 50, while in men it was around 60 years of age (Maltais et al., 2009). The quality of life of older people is strongly affected by functional autonomy, and physical exercise is an important protector and precursor to autonomy (Esain et al.). Therefore, strategies that promote active aging, coupled with compensatory strategies, induce a higher quality of life for the elderly population (Teixeira et al., 2010). Resistance exercise (RE) is a common strategy to aid in the treatment of sarcopenia using the traditional model with high-load exercise ( $\geq 70 \%$ of $1 \mathrm{RM})$ using machines or body weight. However, alternative strategies have been applied, such as low load training (20-30\% of 1RM) associated with peripheral vascular occlusion, resulting in changes in strength and muscle mass (Cook et al., 2017).

\footnotetext{
${ }^{1}$ Multidisciplinary Research Nucleus in Physical Education (NIMEF), Federal University of Tocantins (UFT), Tocantinópolis, Brazil.

${ }^{2}$ Research Center for Sport and Physical Activity, CIDAF (UID/PTD/04213/2016), Faculty of Sports Sciences and Physical Education - University of Coimbra, Portugal (FCDEF-UC).

${ }^{3}$ University Catholic Center of Quixadá - UNICATÓLICA, Quixadá, Ceará, Brazil.
} 
Although changes in strength and muscle mass are observed with blood flow restriction (BFR) exercise, the influence of this method on the functional capacity indices in elderly sarcopenic women following an exercise program over an extended period needs to be determined. Studies using this methodology have verified the chronic responses for about 6-16 weeks, but few studies have verified physical function in the elderly for a longer period (Hughes et al., 2017). The goal of this study was to compare the functional capacity of elderly women and the rates of sarcopenia after 16 weeks of intervention with exercise and BFR.

\section{MATERIAL AND METHOD}

Participants. This study protocol (SP) is part of a doubleblind, randomized-controlled, parallel trial with intervention based on an exercise protocol. This SP is enrolled in the Brazilian Registry of Clinical Trials (ReBEC) under number (RBR-2xfgdh).

Twenty-three women were randomly allocated into two groups, low-intensity exercise with blood flow restriction ( $\mathrm{LI}+\mathrm{BFR}, \mathrm{N}=11$, Age: $69.40 \pm 5.73$ ) and control group (CG, $\mathrm{N}=12$, Age: $69.00 \pm 6.39$ ) (Fig. 1). Participants were randomized in a ratio (1:1) by members of the research team who were not involved in the evaluations. A random number generator was used (www.randomization.com) to allocate the participants to the groups. Participants did not know what exercise intervention they would participate in and were instructed not to discuss their experiences with other study participants to maintain the double-blinding study feature.

The inclusion criteria were: a) age equal to or greater than 60 years; b) have no muscle and / or joint limitations in the involved segments; and c) have medical release for participation. The exclusion criteria were: a) unable to carry out the initial evaluations; b) to have Muscle Mass Index (MMI) above of $5.45 \mathrm{~kg} / \mathrm{m}^{2}$; and c) to have two consecutive absences or four interspersed in the intervention sessions. All participants were informed about the methodological procedures and signed a Free and Clarified Consent Term (FCCT). The study respected the ethical procedures for research in humans (Res. 466/2012 of the National Health Council) and the Declaration of Helsinki. The protocol was approved by the Ethics and Research Committee of Unicatólica ( $\left.\mathrm{n}^{\circ} 1175.175\right)$.

Study Design. SP lasted 18 weeks, 16 of which were direct intervention with training frequency of 3 times per week and 2 weeks for initial and final evaluations. Each session had a maximum duration of 40-50 minutes divided into three parts: a) 10 minutes to warm-up, with standing or sitting exercises of joint mobilization and exercises to promote respiratory body awareness; b) 20 minutes of direct intervention. The LI + BFR group had a volume of 75 repetitions at $20-30 \%$ of $1 \mathrm{RM}$ and 3-4 sets per exercise (30, 15,15 and repetitions with 30 " rest between sets). The pneumatic cuffs were positioned in proximal portion of the limbs. Once pneumatic cuffs were inflated, they remained inflated for all exercises, including the rest periods between sets and deflated during exercise transition (90"). The selected exercises were: Leg Squat, Leg Press, Leg Extension/flexion and Stand plantar flexion. The LI + BFR group trained under supervision and the $C G$ was not submitted to any kind of exercise and only participated in the evaluations. All interventions performed with exercises were recorded and the participants had full follow-up during the period.

A perceived effort scale (OMNI) was used for the exercises in BFR group for adjustment of relative exercise intensities.

Blood flow restriction. To determine the occlusion pressure of the participants submitted to the exercise with BFR, a specific tourniquet sphygmomanometer with dimensions of 13 x $83 \mathrm{~cm}$ (Hokanson SC12, Maidenhead, Berkishire) was used in the legs. After 5 minutes of rest in the supine position, a vascular Doppler (DV-601, Marted®, São Paulo, Brazil) was placed in the tibial artery of the participants in order to obtain the auscultatory pulse. The cuff was inflated until the Doppler sound interruption and the recorded values (in $\mathrm{mmHg}$ ). The cuff pressure used in exercise with BFR was stipulated as $80 \%$ of the total blood flow interruption pressure (Laurentino et al., 2008).

Functional Tests and Sarcopenia Index. Anthropometric assessment followed standard procedures (Chumlea \& Baumgartner, 1989). Weight and height was measured using a portable scale with stadiometer $\left(\right.$ Whelmy ${ }^{\circledR}$, Brazil) with an accuracy of $0.1 \mathrm{~kg}$ and $0.1 \mathrm{~cm}$. Body mass index (BMI) was calculated according the standard formula [BMI = weight/height ${ }^{2}$.

Body fat (\%) was assessed using a four-pole frequency bioelectrical impedance analysis (Maltron $\AA$ BF906 - Maltron International Ltd, Essex, UK).

The functional capacity was evaluated using the tests proposed by Rikli \& Jones (2001), which consists of the following parameters: Chair stand (CS), Arm curl (AC), Sitand-reach(SR), 2.44 m Up-and-go (TUG), Back scratch (BS) and 6 minutes walk test $(6 \mathrm{MW})$. 
Handgrip strength was verified using a manual TKK 5401 dynamometer (GRIP-D ${ }^{\circledR} \quad$ TAKEI Scientific Instruments, Japan) (measuring capacity from 5 to $100 \mathrm{~kg}$, resolution $0.05 \mathrm{~kg}$, accuracy $\pm 0.5 \%$ ).

The appendicular muscle mass was obtained through the equation: Appendicular muscular mass ( $\mathrm{AMM}$ in $\mathrm{kg}$ ) = $0.2487 \times \mathrm{P}(\mathrm{kg})+0.0483 \times$ Heigth $(\mathrm{cm})-0.1584 \times$ Hip perimeter $(\mathrm{cm})+0.0732 \times$ Handgrip strength $(\mathrm{kg})+2.5843$ $x$ Gender +5.8828 . The Muscle Mass Index (MMI) was obtained by the equation: $\mathrm{MMI}=\mathrm{AMM}(\mathrm{kg}) /$ height 2 (m). The classification of MMI was made according to the criteria defined by Baumgartner et al. (1998), considering sarcopenia when the MMI values were lower than $5.45 \mathrm{~kg} /$ $\mathrm{m}^{2}$ and above of 10.85 seconds on the TUG test (Martinez et al., 2015).

Statistical analysis. Normality of the data was verified by the Kolmogorov-Smirnov test. Variables in the baseline were compared using the independent Student's t-test. In the pre and post intervention the Paired Student's t-test was used. Data were presented as values of mean \pm SD. Analyses were conducted in SPSS software version 23.0 (SPSS INC., Chicago, IL, USA). The significance level was set at $\mathrm{p}<0.05$.

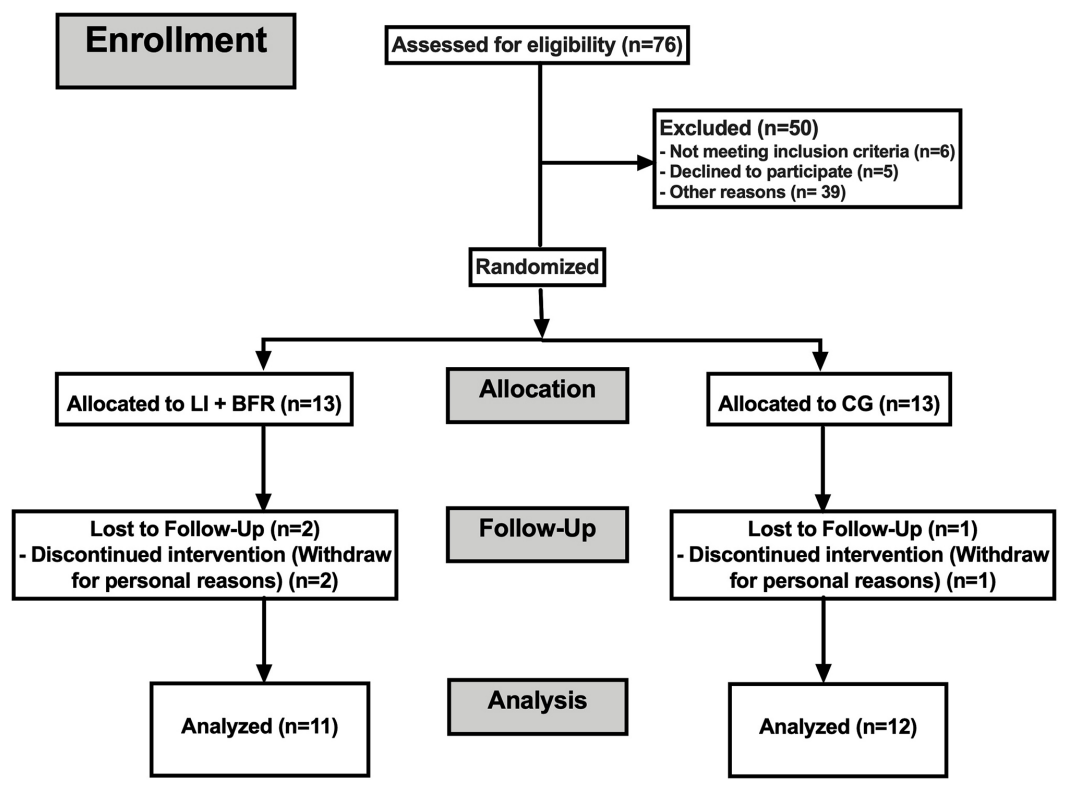

\section{RESULTS}

At baseline, there were no differences between the LI + BFR and CG groups for all anthropometric and physical performance variables $(\mathrm{p}>0.05)$ (Table I).

Figure 2 presents the intra groups comparisons after 16 weeks of intervention. The participants in the LI + BFR group improved the performance in all the functional tests as well as the AMM and MMI index, but still remained classified as sarcopenic.

Fig. 1. Flow chart of participants allocation and follow-up.

Table I. Anthropometric and physical performance variables at baseline.

\begin{tabular}{lccc}
\hline & LI+BFR $(\mathrm{N}=11)$ & $\mathrm{CG}(\mathrm{N}=12)$ & \\
\cline { 2 - 4 } Variables & $\mathrm{M}(\mathrm{SD})$ & $\mathrm{M}(\mathrm{SD})$ & $\mathrm{p}$ value \\
\hline Age $($ years) & $69.40 \pm 5.73$ & $69.00 \pm 6.39$ & .426 \\
Height $(\mathrm{m})$ & $1.53 \pm .038$ & $1.50 \pm .031$ & .121 \\
Weight $(\mathrm{kg})$ & $64.35 \pm 8.45$ & $67.24 \pm 5.28$ & .319 \\
BMI $(\mathrm{kg} / \mathrm{m} 2)$ & $27.09 \pm 2.58$ & $29.60 \pm 1.76$ & .096 \\
Body Fat $(\%)$ & & & \\
Handgrip Strength (Kg) & $23.02 \pm 3.20$ & $23.04 \pm 5.97$ & .432 \\
Appendicular Muscle Mass (Kg) & $9.71 \pm 2.76$ & $9.24 \pm 1.84$ & .356 \\
Muscle Mass Index & $4.06 \pm .96$ & $4.09 \pm .73$ & .218 \\
Chair Stand (reps) & $8.7 \pm .94$ & $7.9 \pm 1.52$ & .862 \\
Arm Curl (reps) & $10.1 \pm 1.50$ & $9.1 \pm .87$ & .346 \\
Sit-and-reach (cm) & $-1.3 \pm 2.20$ & $-2 \pm 3.00$ & .551 \\
2.44m Timed Up-and-Go test (s) & $10.92 \pm 1.76$ & $10.99 \pm 1.65$ & .672 \\
Back Scratch (cm) & $-.65 \pm 1.51$ & $-1.8 \pm 1.63$ & .124 \\
6 minutes walk test (m) & $324.4 \pm 44.86$ & $299.7 \pm 20.4$ & .213 \\
\hline
\end{tabular}



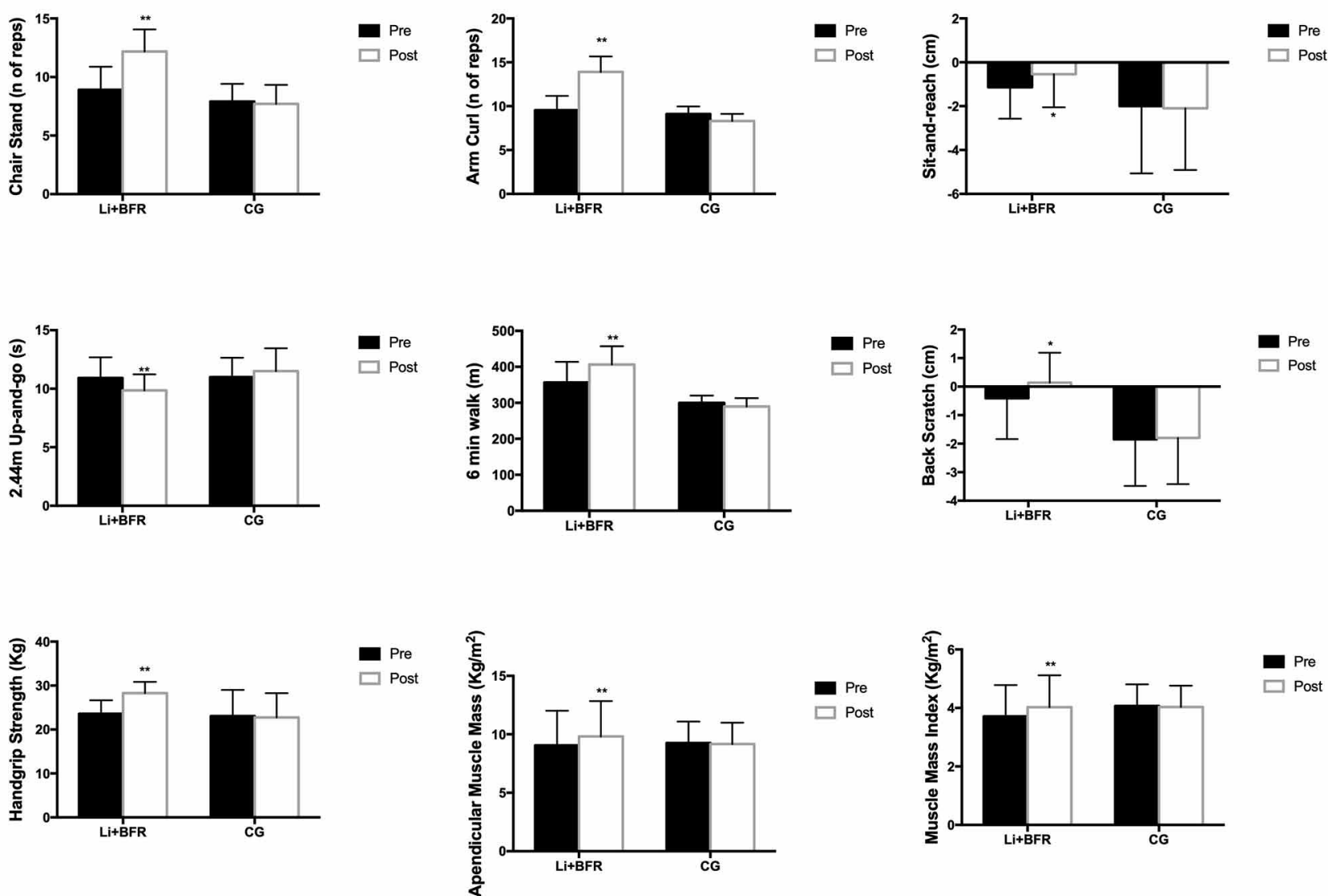

Fig. 2. Comparisons between pre and post intervention. LI+BFR = Low-intensity exercise with blood flow restriction; CG $=\mathrm{Control}$ group; $* \mathrm{p}<0.05, * * \mathrm{p}<0.01$

\section{DISCUSSION}

This is the first study that evaluates physical function with intervention of 16 weeks in elderly women. The main finding of this study was: 16 weeks of direct intervention using the BFR method increased the functional capacity of elderly women and improved the level of sarcopenia rates. The potential effect of the BFR method on increasing strength levels and muscle mass, especially in older adults, has been previously verified (Cook et al.). Performance is believed to be an integrated multifactorial skill, composed of elements such as coordination between the central nervous system and muscle, joint flexibility and muscular strength.

In the results of the present study, it is possible to verify that the women submitted to the exercises with LI + BFR had extremely significant improvement in all analysed variables, which reinforces the potential of applying this method in elderly populations. Eight weeks of exercise with BFR appears to be sufficient to improve the physical function of elderly people living in the community, and such increases, especially in strength and muscle mass, are attributed to exercise-induced growth hormone secretion (Yokokawa $e t$ al., 2008). In addition, BFR exercise may be effective in improving bone health and attenuating muscle atrophy (Hughes et al.).

While the participants in our study were classified as sarcopenic, it is important to note that they did not necessarily have mobility limitations.

Success in physical function tests, such as those used in this study, requires individuals to have a minimum limb strength, but often, additional increases in muscle strength are not translated into additional improvements and changes in the physical profile, such as for example sarcopenia and physical profile.

Exercise with BFR may lead to increased strength and muscle mass in elderly people with reduced mobility, but such increases may not translate into improved quality of life (Cook et al.). 
The 6-minute walk was a measure included in the present study and is associated with aerobic capacity (Enright et al., 2003). The LI + BFR group showed a greater improvement in distance walked during the 6-minute walk after 16 weeks of training compared to $\mathrm{CG}$. To date, the effectiveness of walking with BFR to increase aerobic capacity has not been widely explored. A BFR walk and a BFR cycling studies demonstrated $\mathrm{VO}_{2}$ max increases for young men trained athletes. In a recent study with older adults using a low-intensity walking combined with BFR the results showed increases in physical function beyond an equivalent to non-BFR low-load exercise (Clarkson et al., 2017). However, two studies using walking and BFR, aiming to verify aerobic capacity among older adults, did not show greater increase in aerobic capacity using the BFR method compared to walking without BFR (Ozaki et al., 2011).

Another variable analysed was the $2.44 \mathrm{~m} \mathrm{Up}$-andgo test. In a previous study (Clarkson et al.), the BFR was efficient to improve performance $(12 \pm 2 \%)$ in this test in older adults following 6 weeks of walking exercise. This variable is associated with reaction time and muscle power, dynamic balance and core muscle strength (Santos et al., 2011). This test showed to be a good predictor of sarcopenia in elderly hospitalized patients (Martinez et al.). In addition, this is a parameter that assists in the diagnosis of sarcopenia. The improvements in lower limb strength may explain the better times observed in $2.44 \mathrm{~m} \mathrm{Up-and-go} \mathrm{test} \mathrm{after} 16$ weeks of BFR intervention.

The handgrip strength showed a significant improvement after intervention in LI + BFR group. In a Brazilian study with older women, the handgrip strength losses were associated with sarcopenic obesity (Silva Neto et al., 2012). Sarcopenic obesity, by definition, are low levels of muscle mass with high levels of fat tissue (Tyrovolas et al., 2016). The handgrip strength was positively correlated with anthropometric variables, i.e. body mass, body height and body surface (Chatterjee \& Chowdhuri, 1991).

This study has some limitations. First, the diagnosis of sarcopenia was obtained, in part, based on estimated skeletal muscle mass, which was computed using anthropometric variables. Although there is good sensitivity and specificity with the gold standard technique in previous studies (Lee et al., 2000), including a study with the Brazilian population (Rech et al., 2012), anthropometry is less accurate than other methods (dual energy X-ray absorptiometry, magnetic resonance imaging and computed tomography). Secondly, the study sample had only women, so the results cannot be extrapolated to males.

The BFR method appears to be an effective technique to help the exercise programs for elderly women. Although safe, monitoring of this type of exercise should be done with some caution.

\section{CONCLUSION}

In conclusion, our results showed that exercise conducted with blood flow restriction associated with low intensity resulted in a significant improvement in the functional capacity of elderly women after 16 weeks. Despite the significant results, the intervention period was not sufficient to reverse the pre-sarcopenia condition in elderly women.

\section{ACKNOWLEDGMENTS}

The authors thank the University of Fortaleza (UNIFOR) and also the professionals who participated in the process of daily interventions and evaluations.

LETIERI, R. V.; FURTADO, G. E.; BARROS, P. M. N.; FARIAS, A. M. J.; ANTUNEZ, F. B.; GOMES, B. B. \& TEIXEIRA, A. M. M. B. Efecto del ejercicio de restricción del flujo sanguíneo de 16 semanas sobre la aptitud funcional en mujeres sarcopénicas: un ensayo controlado aleatorio. Int. J. Morphol., 37(1):59-64, 2019.

RESUMEN: Investigamos en mujeres ancianas el efecto de la intervención utilizando el método de restricción del flujo sanguíneo en la capacidad funcional, después de 16 semanas . En un ensayo clínico controlado, 23 mujeres fueron asignadas aleatoriamente en dos grupos; ejercicio de baja intensidad con restricción de flujo sanguíneo (BI + RFS, N = 11, edad: $69,40 \pm 5,73$ ) y grupo control (GC, $N=12$, Edad: 69,00 $\pm 6,39$ ). El grupo BI + RFS tuvo un volumen de 75 repeticiones al $20-30 \%$ de 1 RM y $3-4$ series por ejercicio $(30,15,15$ y repeticiones con $30 "$ de descanso entre series). El GC no fue sometido a ningún tipo de ejercicio. La capacidad funcional, la antropometría y la sarcopenia se verificaron mediante una batería de pruebas antes y después de 16 semanas. El grupo BI + RFS tuvo una mejora significativa en el rendimiento de la fuerza de la empuñadura, soporte de la silla, curvatura del brazo, 2,44 up-and-go y 6 min, 'sit-and-reach' 'Back Scratch' $(\mathrm{p}<0,05)$ después de la intervención. Las mujeres de edad avanzada seguían clasificadas como sarcopénicas, a pesar de la mejora en el índice de masa muscular $(\mathrm{p}<0,01)$. El GC no presentó cambios significativos. El método de restricción del flujo sanguíneo puede ser efectivo en el proceso de intervención utilizando ejercicio físico como estrategia auxiliar en el control de la sarcopenia, proporcionando un perfil físico durante el proceso de envejecimiento.

PALABRAS CLAVE: Entrenamiento de oclusión; Adultos mayores; Fuerza de agarre. 


\section{REFERENCES}

Baumgartner, R. N.; Koehler, K. M.; Gallagher, D.; Romero, L.; Heymsfield, S. B.; Ross, R. R.; Garry, P. J. \& Lindeman, R. D. Epidemiology of sarcopenia among the elderly in New Mexico. Am. J. Epidemiol., 147(8):755-63, 1998.

Chatterjee, S. \& Chowdhuri, B. J. Comparison of grip strength and isomeric endurance between the right and left hands of men and their relationship with age and other physical parameters. J. Hum. Ergol. (Tokyo), 20(1):41-50, 1991.

Chumlea, W. C. \& Baumgartner, R. N. Status of anthropometry and body composition data in elderly subjects. Am. J. Clin. Nutr., 50(5 Suppl.):1158-66; 1989

Clarkson, M. J.; Conway, L. \& Warmington, S. A. Blood flow restriction walking and physical function in older adults: A randomized control trial. J. Sci. Med. Sport, 20(12):1041-6, 2017.

Cook, S. B.; LaRoche, D. P.; Villa, M. R.; Barile, H. \& Manini, T. M. Blood flow restricted resistance training in older adults at risk of mobility limitations. Exp. Gerontol., 99:138-45, 2017.

Cruz-Jentoft, A. J.; Baeyens, J. P.; Bauer, J. M.; Boirie, Y.; Cederholm, T.; Landi, F.; Martin, F. C.; Michel, J. P.; Rolland, Y.; Schneider, S. M.; Topinková, E.; Vandewoude, M.; Zamboni, M. \& European Working Group on Sarcopenia in Older People. Sarcopenia: European consensus on definition and diagnosis: Report of the European Working Group on Sarcopenia in Older People. Age Ageing, 39(4):412-23, 2010.

Enright, P. L.; McBurnie, M. A.; Bittner, V.; Tracy, R. P.; McNamara, R.; Arnold, A.; Newman, A. B. \& Cardiovascular Health Study. The 6-min walk test: a quick measure of functional status in elderly adults. Chest, 123(2):387-98, 2003.

Esain, I.: Rodriguez-Larrad, A.; Bidaurrazaga-Letona, I. \& Gil, S. M. Healthrelated quality of life, handgrip strength and falls during detraining in elderly habitual exercisers. Health Qual. Life Outcomes, 15(1):226, 2017.

Giordano, A.; Bonometti, G. P.; Vanoglio, F.; Paneroni, M.; Bernocchi, P.; Comini, L. \& Giordano, A. Feasibility and cost-effectiveness of a multidisciplinary home-telehealth intervention programme to reduce falls among elderly discharged from hospital: study protocol for a randomized controlled trial. B. M. C. Geriatr., 16(1):209, 2016.

Hughes, L.; Paton, B.; Rosenblatt, B.; Gissane, C. \& Patterson, S. D. Blood flow restriction training in clinical musculoskeletal rehabilitation: a systematic review and meta-analysis. Br. J. Sports Med., 51(13):100311, 2017.

Laurentino, G.; Ugrinowitsch, C.; Aihara, A. Y.; Fernandes, A. R.; Parcell, A. C.; Ricard, M. \& Tricoli, V. Effects of strength training and vascular occlusion. Int. J. Sports Med., 29(8):664-7, 2008.

Lee, R. C.; Wang, Z.; Heo, M.; Ross, R.; Janssen, I. \& Heymsfield, S. B. Total-body skeletal muscle mass: development andcross-validation of anthropometric prediction models. Am. J. Clin. Nutr., 72(3):796-803, 2000.

Maltais, M. L.; Desroches, J. \& Dionne, I. J. Changes in muscle mass and strength after menopause. J. Musculoskelet. Neuronal Interact., 9(4):186-97, 2009.

Martinez, B. P.; Gomes, I. B.; Oliveira, C. S.; Ramos, I. R.; Rocha, M. D.; Forgiarini Júnior, L. A.; Camelier, F. W. \& Camelier, A. A. Accuracy of the Timed Up and Go test for predicting sarcopenia in elderly hospitalized patients. Clinics (Sao Paulo), 70(5):369-72, 2015.

Ozaki, H.; Sakamaki, M.; Yasuda, T.; Fujita, S.; Ogasawara, R.; Sugaya, M.; Nakajima, T. \& Abe, T. Increases in thigh muscle volume and strength by walk training with leg blood flow reduction in older participants. J. Gerontol. A Biol. Sci. Med. Sci., 66(3):257-63, 2011.

Rech, C. R.; Dellagrana, R. A.; Marucci, M. de F. N. \& Petroski, E. L. Validity of anthropometric equations for the estimation of muscle mass in the elderly. Rev. Bras. Cineantropom. Desempenho Hum, 14(1):23$31,2012$.
Rikli, R. E. \& Jones, C. J. Senior Fitness Test Manual. Champaing, Human Kinetics, 2001.

Santos, M. L.; Gomes, W. F.; Pereira, D. S.; Oliveira, D. M.; Dias, J. M.; Ferrioli, E. \& Pereira, L. S. Muscle strength, muscle balance, physical function and plasma interleukin-6 (IL-6) levels in elderly women with knee osteoarthritis (OA). Arch. Gerontol. Geriatr., 52(3):322-6, 2011.

Silva Neto, L. S.; Karnikowiski, M. G.; Tavares, A. B. \& Lima, R. M. Association between sarcopenia, sarcopenic obesity, muscle strength and quality of life variables in elderly women. Rev. Bras. Fisioter. 16(5):360-7, 2012.

Teixeira, L. E.; Silva, K. N.; Imoto, A. M.; Teixeira, T. J.; Kayo, A. H.; Montenegro-Rodrigues, R.; Peccin, M. S. \& Trevisani, V. F. Progressive load training for the quadriceps muscle associated with proprioception exercises for the prevention of falls in postmenopausal women with osteoporosis: a randomized controlled trial. Osteoporosis Int., 21(4):589-96, 2010

Tieland, M.; Trouwborst, I. \& Clark, B. C. Skeletal muscle performance and ageing. J. Cachexia Sarcopenia Muscle, 9(1):3-19, 2017.

Tyrovolas, S.; Koyanagi, A.; Olaya, B.; Ayuso-Mateos, J. L.; Miret, M.; Chatterji, S.; Tobiasz-Adamczyk, B.; Koskinen, S.; Leonardi, M. \& Haro, J. M. Factors associated with skeletal muscle mass, sarcopenia, and sarcopenic obesity in older adults: a multi-continent study. $J$. Cachexia Sarcopenia Muscle, 7(3):312-21, 2016.

World Health Organization. Ageing and Health. Geneva, World Health Organization, 2018. Available from: http://www.who.int/news-room/ fact-sheets/detail/ageing-and-health

Yokokawa, Y.; Hongo, M.; Urayama, H.; Nishimura, T. \& Kai, I. Effects of low-intensity resistance exercise with vascular occlusion on physical function in healthy elderly people. Biosci. Trends, 2(3):117-23, 2008.

Corresponding author:

Rubens Vinícius Letieri

Universidade Federal do Tocantins (UFT).

Avenida Nossa Senhora de Fátima, 1558 - Centro

Tocantinópolis-TO

BRASIL

Email: rubens.letieri@gmail.com

Received: $10-07-2018$

Accepted: 01-10-2018 